\title{
Multi-Gaussian-DAEM-reaction model for thermal decompositions of cellulose, hemicellulose and lignin: Comparison of $\mathrm{N}_{2}$ and $\mathrm{CO}_{2}$ atmosphere
}

\author{
Jinzhi Zhang ${ }^{\mathrm{a}, \mathrm{b}}$, Tianju Chen ${ }^{\mathrm{a}, *}$, Jingli $\mathrm{Wu}^{\mathrm{a}}$, Jinhu $\mathrm{Wu}^{\mathrm{a}, *}$ \\ a Key Laboratory of Biofuels, Qingdao Institute of Bioenergy and Bioprocess Technology, Chinese Academy of Sciences, 189 Songling Road, Qingdao 266101, China \\ ${ }^{\mathrm{b}}$ University of Chinese Academy of Sciences, Beijing 100049, China
}

\section{A R T I C L E I N F O}

\section{Article history:}

Received 2 April 2014

Received in revised form 8 May 2014

Accepted 11 May 2014

Available online 20 May 2014

\section{Keywords:}

Distributed activation energy model

(DAEM)

Thermogravimetric analysis (TGA)

Kinetic analysis

Pyrolysis

Gasification

\begin{abstract}
A B S T R A C T
Thermal decompositions of three components of biomass (cellulose, hemicellulose and lignin) were studied using nonisothermal thermogravimetric analysis (TGA) under both oxidative and inert atmospheres at a heating rate of $10 \mathrm{~K} \mathrm{~min}^{-1}$. The multi-Gaussian-distributed activation energy model (DAEM)-reaction model was first developed to describe thermal decomposition behaviors of three components. Results showed that the presence of $\mathrm{CO}_{2}$ enhanced the thermal decompositions of three components in high temperature range, but made little difference in low temperature range. Decomposition behaviors under $\mathrm{CO}_{2}$ were analyzed by the two-stage reaction mechanism corresponding to the pyrolysis process of original materials and the gasification process of char. During gasification stage, $\mathrm{CO}_{2}$ was reduced to $\mathrm{CO}$, which provided a possibility of a reduction in greenhouse gas emissions. In addition, more $\mathrm{CO}$ was produced, and therefore the thermal value of gas was improved. The findings imply that $\mathrm{CO}_{2}$ gasification technology of biomass has great research significance.
\end{abstract}

(c) 2014 Elsevier Ltd. All rights reserved.

\section{Introduction}

Biomass is a clean, $\mathrm{CO}_{2}$ neutral and renewable energy source, whose energy utilization creates less environmental pollution than fossil fuels do (Zou et al., 2010). The scarcity of fossil fuels and the environmental problems associated with climate change have led to a growing interest in the production of alternative fuels from biomass (White et al., 2011). Among various conversion technologies, thermochemical conversion is one of the most promising technologies for generation of energy from biomass (Shen et al., 2011a). Pyrolysis and gasification are two key thermochemical conversion technologies for utilizing biomass. Pyrolysis is the first step in the thermochemical conversion of biomass materials, which can be described as the thermal degradation of organic matrix in an inert environment to obtain an array of solid, liquid and gas products (Wang et al., 2008). Gasification is requiring high-temperature gasifying agent to react with the organic material, which can generate a gas mixture of carbon monoxide, hydrogen and methane, together with carbon dioxide which is suitable for direct use in combined cycle gas turbine systems or can be used as syngas (Senneca, 2007). A thorough knowledge of biomass

\footnotetext{
* Corresponding authors. Tel.: +86 53280662763.

E-mail addresses: chentianju27@gmail.com (T. Chen), wujh@qibebt.ac.cn (J. Wu).
}

pyrolysis and gasification kinetic investigations is required for the simulating reactor design and optimization process operation. In addition, kinetic data gives valuable information and future direction for planning an industrial process. Suitable reactors must be constructed and operated based on reliable knowledge of how biomass decompose.

Thermogravimetric analysis (TGA) has been widely used for online monitoring of thermal decomposition process of solid state materials such as coals (de Caprariis et al., 2012) and biomass (Ahmaruzzaman and Sharma, 2013). The thermal decomposition involves many different reactions because of the chemical complexity of biomass materials (Cai et al., 2013b). Besides trace amount of extractives and minerals, biomass was mainly composed of three major components (cellulose, hemicellulose and lignin) (Wang et al., 2008). Previous studies indicated that it was important to distinguish behaviors of the three components for a better understanding of the biomass pyrolysis process (Yang et al., 2005). There are a variety of models available for analyzing biomass thermal decomposition kinetics, including first-order (Kissinger, 1956), nth-order (Kissinger, 1957), nucleation (Chen et al., 1993), discrete activation energy distributions (Burnham and Braun, 1998), and sequential models (Braun and Burnham, 1987) such as models having Gaussian (Anthony and Howard, 1976), Weibull (Lakshmanan and White, 1994) and Gamma 
(Astarita, 1989) distributions. The distributed activation energy model (DAEM), as one kind of the sequential models, is by far the most comprehensive model for analyzing complex reactions such as pyrolysis of biomass (Várhegyi et al., 2010). The model assumes that an infinite number of first-order parallel reactions having unique kinetic parameters take place concurrently. A continuous distribution function is used to represent the activation energies from various reactions. The surrounding atmosphere of the reaction system has great influence on the biomass thermal decomposition process (White et al., 2011). It has long been known that the thermal decomposition of wood in air is greater than in vacuum (Stamm, 1956). A large number of literatures (Cai et al., 2013a; White et al., 2011; Zhou et al., 2013) are available about the research of biomass pyrolysis in inert atmosphere. However, there is relatively scarce research about the thermal decomposition kinetics of biomass under oxidative atmosphere such as $\mathrm{CO}_{2} \cdot \mathrm{CO}_{2}$ gasification of biomass is a thermochemical conversion of solid material into a gaseous energy carrier. The producer gas from the $\mathrm{CO}_{2}$ gasification process then can be upgraded into bio-syngas, a gas rich in $\mathrm{CO}$ and $\mathrm{H}_{2}$ which can be used for production of various liquid fuels or other organic chemicals. In addition, $\mathrm{CO}_{2}$ gasification of biomass char would offer a potential solution for the alleviation of greenhouse gas emission. Therefore, $\mathrm{CO}_{2}$ gasification of biomass is of important research significance.

The gasification kinetics of cellulose, hemicellulose and lignin in $\mathrm{CO}_{2}$ atmosphere were investigated by Chen et al. (2014), and the idea of fitting DTG curves with several Gaussian distribution models was proposed. A isoconversional model called Friedman's method was used to determine the kinetic parameters. However, the description of isoconversional model was complicated, and at least there paris of weight loss datas at different heating rates were needed. Recently, DAEM with the Gaussian distribution for activation energies has been widely used for analyzing thermal decomposition of biomass (Cai et al., 2013b; Gašparovič et al., 2012). A double Gaussian-DAEM-reaction model was proposed in the work of Zhang et al. (2014) to more correctly describe the pyrolysis kinetics under $\mathrm{N}_{2}$ atmosphere for hemicellulose and lignin. Nevertheless, the double Gaussian-DAEM-reaction model could no correctly predict thermal decomposition behaviors of hemicellulose and lignin under $\mathrm{CO}_{2}$ atmosphere because of limited Gaussian peaks. What's more, three kinetic parameters (including $k_{0}, E_{0}$ and $\sigma$ ) were optimized without considering the interrelation between $k_{0}$ and $E_{0}$ (the so-called compensation effect). The main objective of the present work was to gain a better understanding of the decomposition behaviors of cellulose, hemicellulose and lignin in $\mathrm{CO}_{2}$ atmosphere compared to those in inert atmosphere. As was well known, the gas of $\mathrm{He}, \mathrm{Ar}$ or $\mathrm{N}_{2}$ was always used for an inert atmosphere, among which $\mathrm{N}_{2}$ was selected in this work because of its low cost and widespread use. TGA experiments were performed at a heating rate of $10 \mathrm{~K} \mathrm{~min}^{-1}$. The two-stage reaction mechanism, corresponding to pyrolysis and gasification processes, was proposed to analyze decomposition behaviors under $\mathrm{CO}_{2}$ atmosphere. A novel multi-Gaussian-DAEM-reaction model was developed to investigate the decomposition kinetics of three components of biomass, and the problem of compensation effect was avoided by fixing pre-exponential factor $\left(k_{0}\right)$ at $1.67 \times 10^{13} \mathrm{~s}^{-1}$. Kinetic parameters $\left(E_{0}\right.$ and $\sigma$ ) together with activation energy distributions were all obtained.

\section{Methods}

\subsection{Materials}

Cellulose (CAS: 9004-34-6, product number: C6288) and lignin (CAS: 8068-05-1, product number: 471003) were bought from
Sigma-Aldrich Co., Ltd. (USA). Cellulose was a polysaccharide composed of long chains of $\beta(1,4)$ linked D-glucose units. The low sulfonate content alkali lignin was chosen in this study. Xylan has been widely utilized as a representative of hemicellulose in kinetic study, because commercial hemicellulose can hardly be purchased. In this work, xylan (CAS: 9014-63-5, product number: X4252) was purchased from Sigma-Aldrich Co., Ltd. And xylan was refined from the beech wood. All samples were dried for $12 \mathrm{~h}$ at $378 \mathrm{~K}$ to remove water before the TGA experiment. The overall ash content for cellulose, hemicellulose and lignin were $0,0.48 \%$ and $11.6 \%$, respectively.

\subsection{Experimental procedures}

Thermal decompositions of samples (cellulose, hemicellulose and lignin) were observed in terms of the overall mass loss by using a thermogravimetric analyzer (TGA Q5000 V3.15 Build 263). The temperature was increased from 313.15 to $1273.15 \mathrm{~K}$ at a heating rate of $10 \mathrm{~K} \mathrm{~min}^{-1}$ for all samples. When experiments were performed under $\mathrm{N}_{2}$ atmosphere, nitrogen was continuously passed into the furnace at a flow rate of $100 \mathrm{~mL} \mathrm{~min}^{-1}$. As for experiments under $\mathrm{CO}_{2}$ atmosphere, $\mathrm{CO}_{2}$ and $\mathrm{N}_{2}$ were both used as the purge gas at a flow rate of $80 \mathrm{~mL} \mathrm{~min}^{-1}$ for $\mathrm{CO}_{2}$ and $20 \mathrm{~mL} \mathrm{~min}^{-1}$ for $\mathrm{N}_{2}$.

\subsection{Equations of nonisothermal DAEM}

The DAEM has been widely utilized in analyzing complex reactions such as thermal decompositions of biomass (Shen et al., 2011b). When it is applied to represent the change in total volatiles of nonisothermal decomposition process, the model is expressed as:

$\alpha(T)=\int_{0}^{\infty}\left\{1-\exp \left[-\frac{k_{0}}{\beta} \int_{0}^{T} \exp \left(-\frac{E}{R T}\right) d T\right]\right\} f(E) d E$

where $\alpha$ is extent of conversion, $T$ is the absolute temperature, $k_{0}$ is the pre-frequency factor (frequency factor), $\beta$ is the heating rate, $E$ is the activation energy, $R$ is the universal gas constant, and $f(E)$ is the activation energy distribution.

The activation energy has a continuous distribution in the DAEM. In order to estimate the values of kinetic parameters, the activation energy distribution is generally assumed by a Gaussian distribution with mean activation energy $E_{0}$ and standard deviation $\sigma$ as shown below:

$f(E)=\frac{1}{\sigma \sqrt{2 \pi}} \exp \left[-\frac{\left(E-E_{0}\right)^{2}}{2 \sigma^{2}}\right]$

The derivative of Eq. (1) is expressed as:

$$
\begin{aligned}
\frac{d \alpha(T)}{d T}= & \frac{1}{\sigma \sqrt{2 \pi}} \int_{0}^{\infty} \frac{k_{0}}{\beta} \\
& \times \exp \left[-\frac{E}{R T}-\frac{k_{0}}{\beta} \int_{0}^{T} \exp \left(-\frac{E}{R T}\right) d T-\frac{\left(E-E_{0}\right)^{2}}{2 \sigma^{2}}\right] d E
\end{aligned}
$$

Both temperature integral and integral of the activation energy in Eq. (3) have no exact analytical solution, but can be solved numerically. In this study, a computer program has been created in MATLAB to perform the numerical calculation of Eq. (3).

For the purpose of determining kinetic parameters $\left(k_{0}, E_{0}\right.$ and $\left.\sigma\right)$ of nonisothermal DAEM equations, the objective function based on conversion rate $(d \alpha / d T)$ data is defined according to the following equation:

$S=\sum_{i=1}^{\mathrm{n}_{\mathrm{d}}}\left[\left(\frac{d \alpha}{d T}\right)_{\exp , i}-\left(\frac{d \alpha}{d T}\right)_{\mathrm{cal}, i}\right]^{2}$ 
where $n_{\mathrm{d}}$ is the number of the data points, $(d \alpha / d T)_{\exp }$ represents the experimental data of conversion rate, and $(d \alpha / d T)_{\text {cal }}$ represents those calculated by Eq. (3) for a given set of parameters of $k_{0}, E_{0}$ and $\sigma$.

According to Cai et al. (2013a), it is efficient to solve the optimization problem by using pattern search method, which is a derivative-free direct search algorithm. Here the pattern search method was utilized to optimize the values of kinetic parameters in DAEM.

A problem involving the estimation of kinetic parameters is that different pairs of $k_{0}$ and $E_{0}$ values provide an equally good fit to experimental data. The existence of non-uniqueness of kinetic parameters is the so-called compensation effect (Holstein et al., 2005). For this reason, the value of pre-exponential factors was often fixed and selected in such a way so that it is consistent with the transition-state theory $\left(k_{0} \approx 10^{11}-10^{16} \mathrm{~s}^{-1}\right)$ (Várhegyi et al., 2010). In most cases, a value of $k_{0}=1.67 \times 10^{13} \mathrm{~s}^{-1}$ was found to be adequate, which was taken for the pre-exponential factor of the biomass pools (Fiori et al., 2012). Given that, it was assumed in this study that thermal decompositions of all samples shared the same pre-exponential factor, and its value was fixed at $1.67 \times 10^{13} \mathrm{~s}^{-1}$. According to the value range of $E_{0}$ and $\sigma$ reported in the literature (Várhegyi et al., 2010), the expected range of $E_{0}$ was selected from 50 to $350 \mathrm{~kJ} \mathrm{~mol}^{-1}$, and $\sigma$ was selected from 0.1 to $50 \mathrm{~kJ} \mathrm{~mol}^{-1}$.

The kinetic parameters of DAEM estimated from the pattern search method were used to generate a curve of $d \alpha / d T$ which was compared with the one obtained from TGA experiments by the fitting quality. The determination of the best-fit parameters was achieved through the average deviation between the calculated and experimental curves. The value of Fit was defined as below:

Fit $(\%)=100 \times \frac{\sqrt{\frac{s}{n_{d}}}}{\left(\frac{d \alpha}{d T}\right)_{\max }}$

where $(d \alpha / d T)_{\max }$ is the maximum experimental value of conversion rate. It is obvious that a lower value of Fit indicates a better quality of fitness.

\section{Results and discussion}

\subsection{Effects of atmosphere on thermal decompositions of cellulose, hemicellulose and lignin}

To explore effects of the surrounding atmosphere on the thermal decompositions of cellulose, hemicellulose and lignin, TGA results in $\mathrm{N}_{2}$ and $\mathrm{CO}_{2}$ atmospheres were compared (Fig. 1). Characteristic parameters during thermal decomposition of three samples under $\mathrm{N}_{2}$ and $\mathrm{CO}_{2}$ atmospheres were summarized in Table 1. Although the thermogravimetric (TG) curve of cellulose under $\mathrm{CO}_{2}$ in low temperature range showed a similar trend with that under $\mathrm{N}_{2}$ atmosphere, differences can be observed in high temperature range. As shown in Fig. 1a, the final residue mass of cellulose remain unchanged under $\mathrm{N}_{2}$ atmosphere when temperature was higher than $850 \mathrm{~K}$. However, the final residue mass of cellulose decreased slowly during the same temperature range (850-1200 K) under $\mathrm{CO}_{2}$ atmosphere. As for the derivative thermogravimetric (DTG) curves, only one sharp mass loss stage (Stage I) was observed for cellulose decomposition under $\mathrm{N}_{2}$ atmosphere. When $\mathrm{N}_{2}$ was replaced by $\mathrm{CO}_{2}$, another mass loss stage (Stage II) was observed (Fig. 1b). Here, the temperature corresponding to the minimum in the DTG curve was regarded as the point of separation between two mass-loss stages. As shown in Fig. 1c and d, thermal decomposition behaviors of hemicellulose changed with atmosphere significantly at temperature higher than $850 \mathrm{~K}$. TG and DTG curves of hemicellulose under $\mathrm{N}_{2}$ atmosphere exhibited a single distinct stage (Stage I) of mass loss. However, when $\mathrm{CO}_{2}$ was used as the carrier gas, the second distinct stage (Stage II) was observed in the temperature range of $850-1200 \mathrm{~K}$. As shown in Fig. $1 \mathrm{e}$ and $\mathrm{f}$, although thermal decompositions of lignin under $\mathrm{N}_{2}$ and $\mathrm{CO}_{2}$ atmospheres both exhibited two distinct stages (Stage I and Stage II) of mass loss, the DTG curve under $\mathrm{CO}_{2}$ atmosphere had a stronger peak in Stage II (Fig. 1f). More specifically, the second peak in $\mathrm{CO}_{2}$ atmosphere was very acute, since the maximum value ( DTG $_{2}$ in Table 1 ) was about 6 times bigger than the corresponding value of DTG $\mathrm{DT}_{2}$ in $\mathrm{N}_{2}$ atmosphere. These findings indicated that the presence of $\mathrm{CO}_{2}$ promoted the decomposition of cellulose, hemicellulose and lignin during high temperature range (Stage II, $850-1200 \mathrm{~K}$ ), and similar results were reported in thermal degradation of municipal solid waste (Lai et al., 2012).

When experiments were performed under $\mathrm{N}_{2}$ atmosphere, the thermal degradation during the whole temperature range was referred to as a two-stage pyrolysis process. Stage I was characterized by a major weight loss in the TG curve, which corresponded to the main pyrolysis process with a strong peak in the DTG curve. During this stage, most of the organic materials were decomposed, resulting in the formation of char (Chen et al., 2014). During the reaction of Stage II, the carbonaceous matters in char continuously decomposed at a very slow rate, with a slight continued weight loss in the TG curve. Zou et al. (2010) gave a detailed explanation about the pyrolysis process. When experiments were performed under $\mathrm{CO}_{2}$ atmosphere, Stage I was recognized as the pyrolysis process, which was similar to the reaction process of Stage I under $\mathrm{N}_{2}$ atmosphere. Stage II was considered as the gasification process, which went from 850 to $1200 \mathrm{~K}$. During the reaction of Stage II, char reacted with $\mathrm{CO}_{2}$, and more combustible gas such as $\mathrm{CO}$ was produced, leading to much greater weight loss (Chen et al., 2006, 2014 ). This can explain why the final residue mass (at $1200 \mathrm{~K}$ ) of cellulose, hemicellulose and lignin in $\mathrm{CO}_{2}$ (3.24\%, 6.36\% and $18.76 \%$, respectively) was lower than that under $\mathrm{N}_{2}$ atmosphere (4.42\%, 20.44\% and 51.23\%, respectively), as shown in Table 1 . Unlike pyrolysis under inert atmosphere, $\mathrm{CO}_{2}$ was involved in gasification reactions under oxidative atmosphere, and was reduced to CO (Chen et al., 2006), which provided a possibility of a reduction in greenhouse gas emissions. Furthermore, more CO was produced, and therefore the thermal value of gas was improved. CO covers a wide range of industrial applications. It can either be used as reductive gas, or in direct combustion heating process. Consequently, $\mathrm{CO}_{2}$ gasification technology of biomass has important research significance.

According to Table 1, the residue mass under $\mathrm{CO}_{2}$ atmosphere at $850 \mathrm{~K}$ were $6.62 \%, 30.81 \%$ and $68.45 \%$ for cellulose, hemicellulose and lignin, respectively, which were slightly larger than the corresponding values under $\mathrm{N}_{2}$ atmosphere (4.30\%, 27.10\% and 64.33\%). These results indicated that the presence of $\mathrm{CO}_{2}$ slightly suppressed the pyrolysis reactions of Stage I (400-850 K). Possible reasons are that the density and transport property of the two gases are quite different (the mass of the $\mathrm{CO}_{2}$ molecule is different from that of $\mathrm{N}_{2}$ ), and the reaction rate of char gasification by $\mathrm{CO}_{2}$ during low temperature range is very low (Li et al., 2009). Only when temperature increased to or above $850 \mathrm{~K}, \mathrm{CO}_{2}$ has reaction activity, and starts to react with char, which agrees well with the findings of Lai et al. (2012).

\subsection{Different thermal decomposition behaviors of cellulose, hemicellulose and lignin}

It is well known that the ratio of cellulose, hemicellulose and lignin in a biomass differs with the source of the biomass. These three components have significantly different thermal stabilities. Therefore, it is important to have a through contrastive analysis 

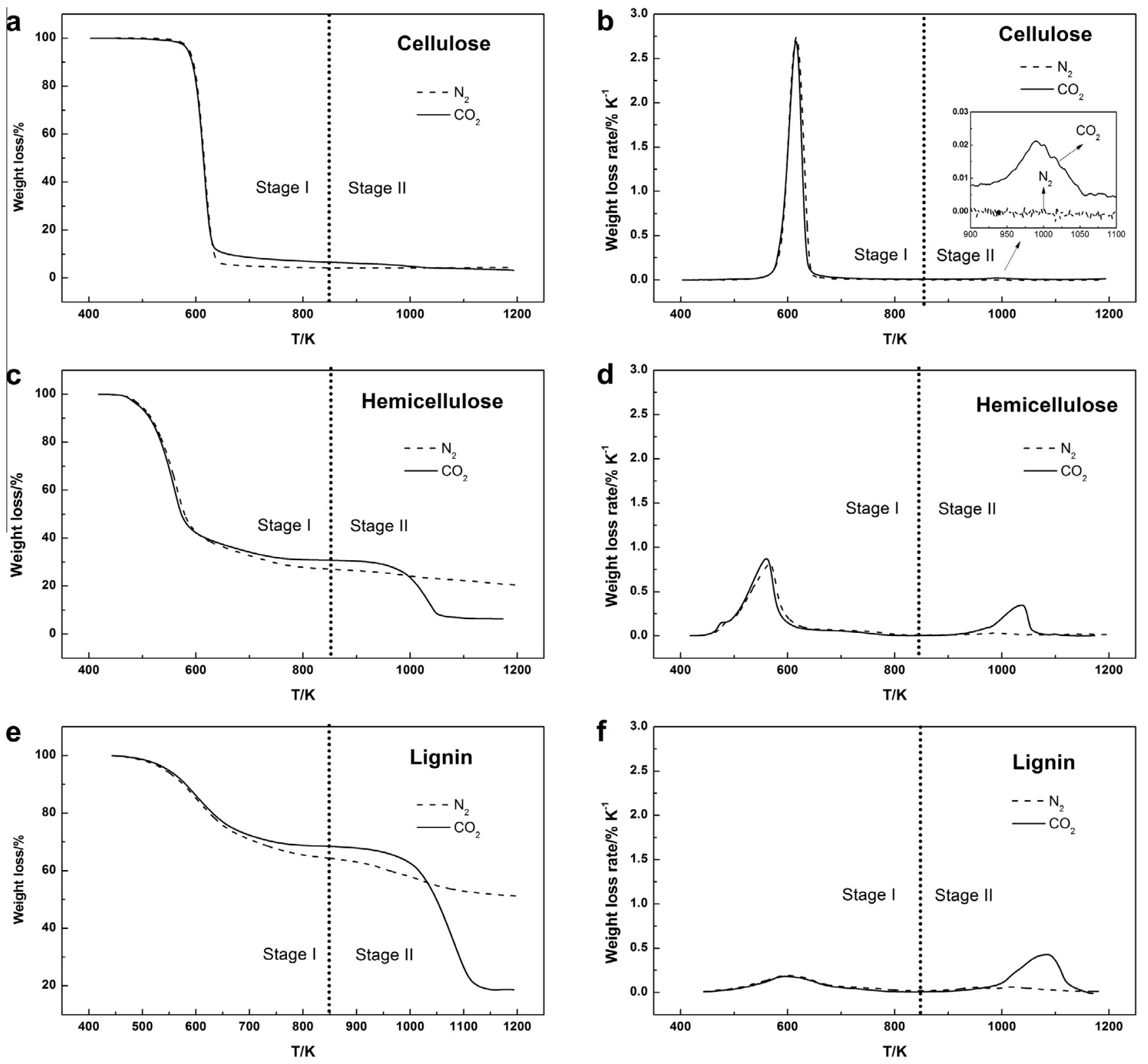

Fig. 1. TG and DTG curves of cellulose, hemicellulose and lignin under different atmospheres $\left(\mathrm{N}_{2}\right.$ and $\left.\mathrm{CO}_{2}\right)$.

Table 1

Characteristic parameters for thermal decomposition of cellulose, hemicellulose and lignin under $\mathrm{N}_{2}$ and $\mathrm{CO}_{2}$ atmospheres.

\begin{tabular}{|c|c|c|c|c|c|c|c|c|}
\hline Atmosphere & Sample & $T_{0}{ }^{\mathrm{a}}(\mathrm{K})$ & $\mathrm{DTG}_{1}{ }^{\mathrm{b}}(\% / \mathrm{K})$ & $T_{1}^{\mathrm{c}}(\mathrm{K})$ & $\mathrm{DTG}_{2}{ }^{\mathrm{d}}(\% / \mathrm{K})$ & $T_{2}^{\mathrm{e}}(\mathrm{K})$ & Residue mass at $850 \mathrm{~K}(\%)$ & Residue mass at $1200 \mathrm{~K}(\%)$ \\
\hline \multirow[t]{3}{*}{$\mathrm{N}_{2}$} & Cellulose & 565 & 2.74 & 616 & - & - & 4.30 & 4.42 \\
\hline & Hemicellulose & 450 & 0.871 & 567 & - & - & 27.10 & 20.44 \\
\hline & Lignin & 450 & 0.19 & 599 & 0.06 & $954 / 1018$ & 64.33 & 51.23 \\
\hline \multirow[t]{3}{*}{$\mathrm{CO}_{2}$} & Cellulose & 565 & 2.69 & 616 & 0.02 & 990 & 6.62 & 3.24 \\
\hline & Hemicellulose & 450 & 0.808 & 560 & 0.35 & 1038 & 30.81 & 6.36 \\
\hline & Lignin & 450 & 0.18 & 598 & 0.43 & 1084 & 68.45 & 18.76 \\
\hline
\end{tabular}

a $T_{0}$ was onset temperature for decomposition.

b DTG $_{1}$ was maximum DTG value of Stage I.

c $T_{1}$ was the temperature associated to $\mathrm{DTG}_{1}$.

d $\mathrm{DTG}_{2}$ was maximum DTG value of Stage II.

e $T_{2}$ was the temperature associated to $\mathrm{DTG}_{2}$.

of their decomposition behaviors. As shown in Fig. 1, remarkable differences were found among thermal decomposition behaviors of cellulose, hemicellulose and lignin under identical atmosphere.
Differences of decomposition behaviors under $\mathrm{CO}_{2}$ atmosphere were first introduced. Cellulose went through a single distinct weight loss step (the second weight loss step in Stage II was 
relatively quite weak), and had the sharpest DTG profile, which decomposed from 565 to $645 \mathrm{~K}$. The maximum weight loss rate $\left(2.69 \% \mathrm{~K}^{-1}\right)$ was obtained at $616 \mathrm{~K}$. When temperature was higher than $645 \mathrm{~K}$, almost all cellulose was decomposed with a very low solid residue (3.24\%) left. Compared with cellulose, hemicellulose began to decompose earlier ( $450 \mathrm{~K}$ ), and went through two distinct weight loss steps $(450-800 \mathrm{~K}$ and $910-1080 \mathrm{~K})$. As shown in Fig. $1 \mathrm{~b}$, the weight loss rate of hemicellulose reached its first peak value $\left(0.808 \% \mathrm{~K}^{-1}\right)$ at $560 \mathrm{~K}$, but at the same temperature, the decomposition of cellulose just began. These results implied that hemicellulose was easier to be decomposed than cellulose. Compared with the sharper and higher DTG curves of cellulose, the DTG curve of lignin tend to be wide and flat. Lignin began to decompose at almost the same temperature $(450 \mathrm{~K})$ as hemicellulose, but its first peak value $\left(0.18 \% \mathrm{~K}^{-1}\right)$ was about one fifth that of hemicellulose. Similar to hemicellulose, lignin was observed to experience two distinct weight loss steps during wide temperature ranges (450-780 $\mathrm{K}$ and $900-1150 \mathrm{~K}$ ). In addition, lignin decomposed with the highest solid residue (18.76\%) left at $1200 \mathrm{~K}$ among the three samples. These findings confirmed the previous conclusion that hemicellulose was the easiest one to be decomposed, and then was cellulose while lignin was the most difficult one (Wang et al., 2008). The same conclusion applied to pyrolysis processes of three samples under $\mathrm{N}_{2}$ atmosphere as well.

The differences in the inherent chemical structures of the three samples could explain those different decomposition behaviors of cellulose, hemicellulose and lignin (Yang et al., 2007). Cellulose was composed of a very long polymer of glucose without any branches, whose structure was in a good order and very strong. Therefore, cellulose had high thermal stability and decomposed in a narrow temperature range. Different to cellulose, hemicellulose was amorphous and had a lower degree of polymerization, which was easy to degrade. Lignin was highly cross-linked polyphenolic aromatic polymer, and the activity of the chemical bonds in lignin covered a quite wide range, leading to the decomposition of lignin occurring in a wide temperature range.
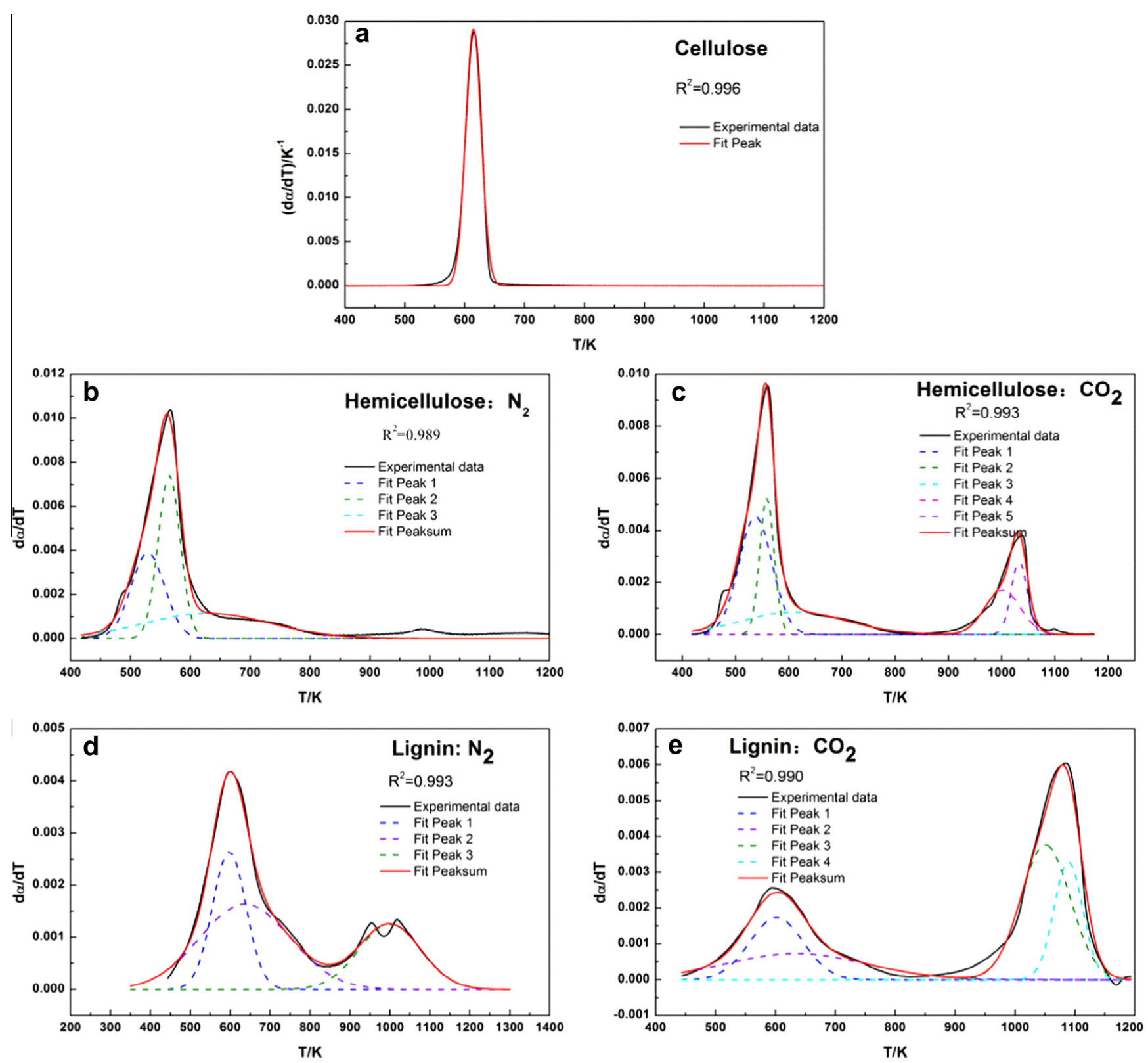

Fig. 2. The conversion rate curves of cellulose, hemicellulose and lignin based on Gaussian distributions. 


\subsection{Kinetic analysis using multi-Gaussian-DAEM-reaction model}

Researchers have made a lot of researches on biomass pyrolysis by using three-parallel-DAEM-reaction model, which assumes three independent parallel reacting pseudocomponents (cellulose, hemicellulose and lignin) (Cai et al., 2013a; Zhou et al., 2013). It is further assumed that the pyrolysis kinetics of each pseudocomponent can be described by the single-Gaussian-DAEM-reaction model. In fact, if we use the single-Gaussian-DAEM-reaction model, the calculated DTG curve will present the shape of standard Gaussian distribution. However, the experimental DTG curves of both hemicellulose and lignin in this work are different from standard Gaussian distribution. Zhou et al. (2013) compared pyrolysis properties of four different kinds of lignin, and it could be found that none of the four DTG curves presented the shape of standard Gaussian distribution, for there existed more than one peak. Consequently, it is not difficult to infer that the singleGaussian-DAEM-reaction model could not describe DTG curves of hemicellulose or lignin correctly. In order to get better agreement with experimental conversion rate data, the multi-peaks method (Chen et al., 2014) was applied in this study (Fig. 2). Given that the surrounding atmosphere had slight effect on thermal decomposition behavior of cellulose, only the conversion rate curve ( $d \alpha / d T$ vs $T$ ) under $\mathrm{N}_{2}$ atmosphere was selected for its kinetic analysis. As shown in Fig. 2a, one Gaussian distribution models could fit the conversion rate curve of cellulose very well, with the correlation coefficient $R^{2}$ of 0.996 . Fig. $2 \mathrm{~b}$ and c showed that the conversion rate curves of hemicellulose under $\mathrm{N}_{2}$ and $\mathrm{CO}_{2}$ atmospheres were closely matched by three and five Gaussian distribution models, respectively $\left(R^{2}>0.99\right)$. And three and four Gaussian distribution models could fit the conversion rate curves of lignin under $\mathrm{N}_{2}$ and $\mathrm{CO}_{2}$ atmospheres very well (with the correlation coefficient $R^{2}>0.99$, Fig. $2 \mathrm{~d}$ and e). Herein, a multi-Gaussian-DAEM-reaction model based on multi-peaks method was developed to describe thermal decomposition behaviors of cellulose, hemicellulose and lignin. In the multi-GaussianDAEM-reaction model, the total data of $d \alpha / d T$ is given by linear combinations of the individual data of $d \alpha_{j} / d T$. Similarly, the total data of $f(E)$ is the linear combinations of the individual data of $f_{j}(E)$. Equations are expressed as:
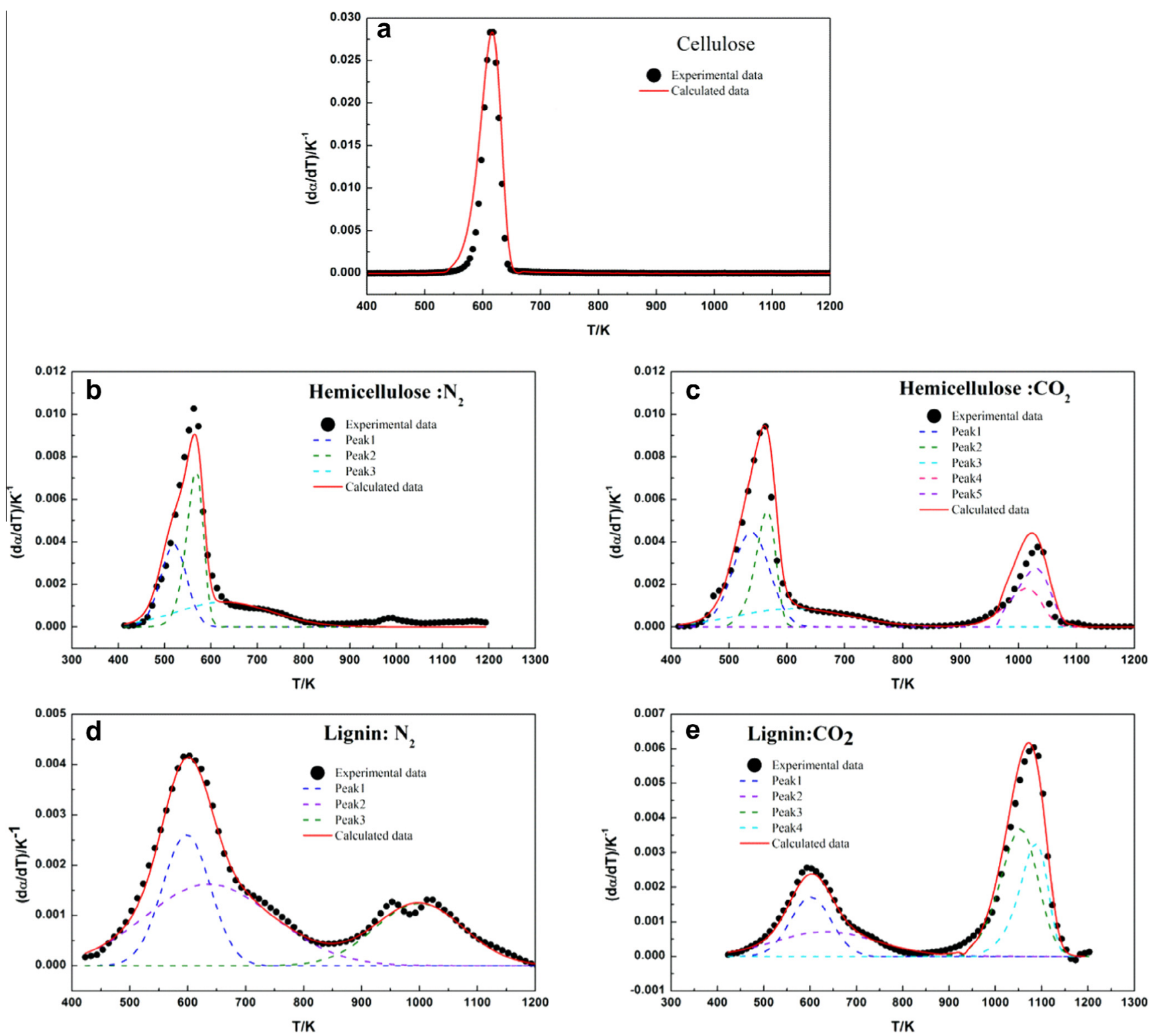

Fig. 3. Experimental and predicted conversion rate curves of cellulose, hemicellulose and lignin. 
$\frac{d \alpha}{d T}=\sum_{j=1}^{n} c_{j} \frac{d \alpha_{j}}{d T}$

$f(E)=\sum_{j=1}^{n} c_{j} f_{j}(E)$

where $c_{j}$ represents the fraction of volatiles produced by the $j$ th peak, and $n$ is the number of fitted peaks.

Fig. 3a showed the results for cellulose from the modeling procedure by the multi-Gaussian-DAEM-reaction model. It can be observed that the calculated data of conversion rate could reproduce the experimental data very well. The kinetic parameters and fitness factor obtained from the fitting procedure were listed in Table 2. The value of fitness factor, Fit, was found to be $4.77 \%$ for cellulose. As shown in Fig. 3a, negligible deviations were found between the fitted and experimental data of $d \alpha / d T$. The calculated mean activation energy, $E_{0}$, was determined to be $179.92 \mathrm{~kJ} \mathrm{~mol}^{-1}$ for cellulose, which was close to the value of $175.6 \mathrm{~kJ} \mathrm{~mol}^{-1}$ reported by Gašparovič et al. (2012).

The results of the fitting procedure using the multi-GaussianDAEM-reaction model for hemicellulose and lignin under $\mathrm{N}_{2}$ and $\mathrm{CO}_{2}$ atmospheres were illustrated in Fig. 3b-e. It was observed that there was a close agreement between the calculated and experimental data of $d \alpha / d T$, with all of the obtained Fit values below $6 \%$. These results implied that it was reasonable to analyze kinetic characteristics of cellulose, hemicellulose and lignin using the multi-Gaussian-DAEM-reaction model. The multiGaussian-DAEM-reaction model provided a good method to accurately predict the pyrolysis and gasification behaviors of biomass, especially for those materials being decomposed through more than one step. As shown in Table 2, the mean activation energies for hemicellulose of Stage I were found to be $158-181 \mathrm{~kJ} \mathrm{~mol}^{-1}$ under $\mathrm{CO}_{2}$ atmosphere, which was close to the results under $\mathrm{N}_{2}$ atmosphere $\left(156-186 \mathrm{~kJ} \mathrm{~mol}^{-1}\right)$; and the same phenomenon was observed for Stage I of lignin $\left(E_{0}=177-189 \mathrm{~kJ} \mathrm{~mol}^{-1}\right.$ in $\mathrm{N}_{2}$ and $E_{0}=178-188 \mathrm{~kJ} \mathrm{~mol}^{-1}$ in $\mathrm{CO}_{2}$ ). Cai et al. (2013b) studied the pyrolysis process of hemicellulose, and obtained the mean activation energy of $178 \mathrm{~kJ} \mathrm{~mol}^{-1}$, which was close to the mean value of activation energy for hemicellulose pyrolysis in this study. Miura and Maki (1998) proposed a simple method for solving the DAEM. Using this method, the maximum activation energy for lignin pyrolysis was determined to be in the range of $158-170 \mathrm{~kJ} \mathrm{~mol}^{-1}$ (Mani et al., 2009). It can be observed that the calculated mean activation

Table 2

Kinetic and statistical parameters for thermal decompositions of cellulose, hemicellulose and lignin.

\begin{tabular}{|c|c|c|c|c|c|}
\hline Atmosphere & Sample & Peak & $E_{0 j}\left(\mathrm{~kJ} \mathrm{~mol}^{-1}\right)$ & $\sigma_{j}\left(\mathrm{~kJ} \mathrm{~mol}^{-1}\right)$ & Fit (\%) \\
\hline \multirow{9}{*}{$\begin{array}{l}\mathrm{N}_{2} / \mathrm{CO}_{2} \\
\mathrm{~N}_{2}\end{array}$} & Cellulose & 1 & 179.92 & 1.539 & 4.77 \\
\hline & \multirow[t]{4}{*}{ Hemicellulose } & & & & \multirow[t]{4}{*}{3.62} \\
\hline & & 1 & 155.70 & 6.778 & \\
\hline & & 2 & 165.80 & 2.017 & \\
\hline & & 3 & 186.29 & 30.828 & \\
\hline & \multirow[t]{4}{*}{ Lignin } & & & & \multirow[t]{4}{*}{2.20} \\
\hline & & 1 & 176.64 & 10.959 & \\
\hline & & 2 & 188.94 & 33.023 & \\
\hline & & 3 & 299.79 & 21.345 & \\
\hline \multirow[t]{11}{*}{$\mathrm{CO}_{2}$} & Hemicellulose & & & & \multirow[t]{6}{*}{5.50} \\
\hline & & 1 & 158.35 & 7.867 & \\
\hline & & 2 & 164.72 & 0.672 & \\
\hline & & 3 & 180.91 & 28.751 & \\
\hline & & 4 & 300.53 & 2.661 & \\
\hline & & 5 & 308.34 & 0.446 & \\
\hline & \multirow[t]{5}{*}{ Lignin } & & & & \multirow[t]{5}{*}{3.62} \\
\hline & & 1 & 177.90 & 11.885 & \\
\hline & & 2 & 188.23 & 33.004 & \\
\hline & & 3 & 314.36 & 7.849 & \\
\hline & & 4 & 322.96 & 0.485 & \\
\hline
\end{tabular}

energies for hemicellulose of Stage I in this work was slightly larger than the values obtained in the above study of Mani et al. This variation was probably due to the differences of the lignin type, calculation methods, as well as the experimental conditions such as heating rate and measurement systems.

Under $\mathrm{CO}_{2}$ atmosphere, the mean activation energies for Stage II for hemicellulose and lignin $\left(301-308 \mathrm{~kJ} \mathrm{~mol}^{-1}\right.$ and $314-323 \mathrm{~kJ} \mathrm{~mol}^{-1}$, respectively) were much larger than the corresponding values during Stage I. Comparing the calculated kinetic parameters with those reported in the literature was not an easy task, because there were many differences in material properties and experimental conditions. Chen et al. (2006) studied the decomposition process of Chinese Gugertree leaf under air atmosphere using a two-step consecutive reaction model, which corresponded to oxidative pyrolysis process of main components and oxidation of char formed. It was observed that the activation energies of the latter step (oxidation of char formed) were larger than those of the former step (oxidative pyrolysis process of main components) when the two obtained pre-exponential factors had the same order of magnitude. Therefore, the trend in present work agreed reasonably well with the trend from the above study of Chen et al. In addition, as for Stage II of the decomposition for lig$\mathrm{nin}$, the values of mean activation energy $\left(314-323 \mathrm{~kJ} \mathrm{~mol}^{-1}\right)$ in $\mathrm{CO}_{2}$ were bigger than that $\left(300 \mathrm{~kJ} \mathrm{~mol}^{-1}\right)$ in $\mathrm{N}_{2}$. In other words, there was a notable increase in the value of activation energy for lignin during Stage II when the inert atmosphere was replaced with an oxidation environment, which agreed well with the findings of Roque-Diaz et al. (1985).

\section{4. $f(E)$ vs $E$}

The $f(E)$ curves for cellulose, hemicellulose and lignin were shown in Fig. 4, it can be seen that the activation energies changed from 130 to $335 \mathrm{~kJ} \mathrm{~mol}^{-1}$. Cai et al. (2010) reported that the activation energy values for solid-state reactions were between 50 and $350 \mathrm{~kJ} \mathrm{~mol}^{-1}$, indicating that the activation energy distribution in this study was reasonable. As shown in Fig. 4a, the range of activation energy for cellulose was $178-182 \mathrm{~kJ} \mathrm{~mol}^{-1}$. The decomposition of cellulose occurred in a narrow temperature range (560-650 K), and a small interval of activation energy $\left(\sigma=1.539 \mathrm{~kJ} \mathrm{~mol}^{-1}\right)$ was confined (Cai et al., 2013b). It was concluded that the activation energies required to decompose different intermediate products were similar. Gaussian distribution of activation energy was widely used for biomass thermal decompositions. Increasing the Gaussian distribution parameter $(\sigma)$ makes the $f(E)$ profile broader (Burnham and Braun, 1998). The decomposition of hemicellulose and lignin both occurred in a wide temperature range, and therefore large interval of activation energy was confined (Fig. 4b-e). The $f(E)$ curves for hemicellulose in $\mathrm{N}_{2}$ and $\mathrm{CO}_{2}$ were shown in Fig. $4 \mathrm{~b}$ and $\mathrm{c}$, respectively. It was found that the activation energy of hemicellulose under $\mathrm{CO}_{2}$ for Stage I was $137-215 \mathrm{~kJ} \mathrm{~mol}^{-1}$, which was similar to that under $\mathrm{N}_{2}$ atmosphere (135$230 \mathrm{~kJ} \mathrm{~mol}^{-1}$ ) but was much lower than that for Stage II under $\mathrm{CO}_{2}\left(295-310 \mathrm{~kJ} \mathrm{~mol}^{-1}\right)$. The $f(E)$ curves for lignin in $\mathrm{N}_{2}$ and $\mathrm{CO}_{2}$ were shown in Fig. 4d and e, respectively. It can be observed that the activation energy of lignin for Stage $\mathrm{I}$ in $\mathrm{CO}_{2}$ was 147$223 \mathrm{~kJ} \mathrm{~mol}^{-1}$, which was similar to that under $\mathrm{N}_{2}$ atmosphere (130-250 $\left.\mathrm{kJ} \mathrm{mol}^{-1}\right)$ and lower than that for Stage II (260$335 \mathrm{~kJ} \mathrm{~mol}^{-1}$ in $\mathrm{N}_{2} ; 295-332 \mathrm{~kJ} \mathrm{~mol}^{-1}$ in $\mathrm{CO}_{2}$ ). During Stage I, the obtained values of activation energies under two different working conditions were similar, indicating that the impact on pyrolysis reactions was quite small when the inert atmosphere was replaced with an oxidation environment (Li et al., 2009). The activation energy in Stage II was larger than that in Stage I, indicating that the activation energy required for char gasification was larger than that for organic materials pyrolysis. 

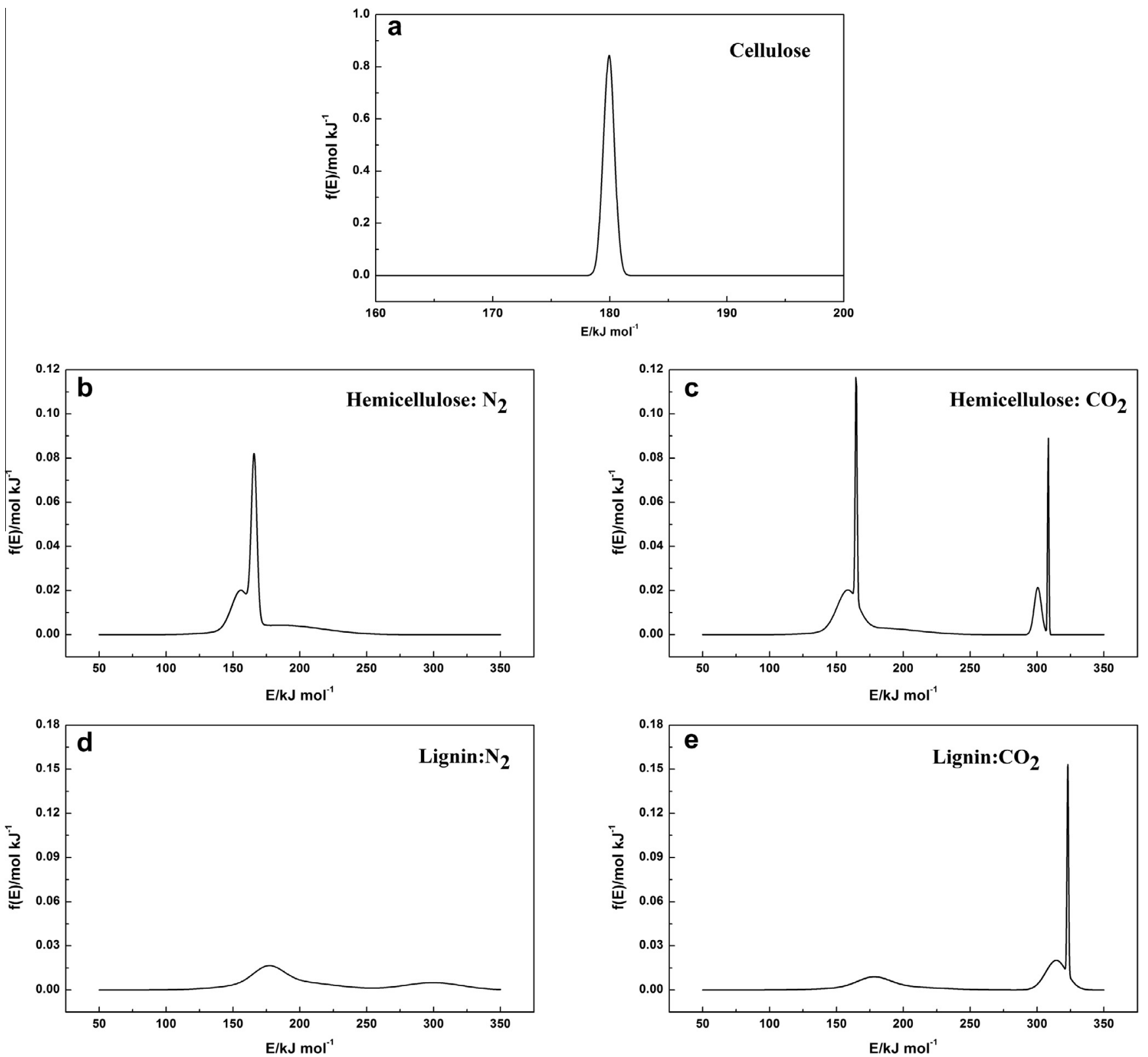

Fig. 4. Activation energy distributions of cellulose, hemicellulose and lignin under $\mathrm{N}_{2}$ and $\mathrm{CO}_{2}$ atmospheres.

\section{Conclusions}

Thermal decomposition behaviors of cellulose, hemicellulose and lignin changed with atmosphere significantly. It was found that the presence of $\mathrm{CO}_{2}$ promoted the thermal decompositions of cellulose, hemicellulose and lignin in high temperature range (850-1200 K). The two-stage reaction mechanism, corresponding to pyrolysis and gasification processes, was proposed to analyze thermal degradation under $\mathrm{CO}_{2}$. The multi-Gaussian-DAEM-reaction model was successfully applied to describe the thermal decomposition behaviors of cellulose, hemicellulose and lignin, and kinetic parameters $\left(k_{0}, E_{0}\right.$ and $\left.\sigma\right)$ were obtained. The activation energy distribution was in the range of $130-335 \mathrm{~kJ} \mathrm{~mol}^{-1}$, which was considered reasonable according to reported literatures.

\section{Acknowledgements}

Financial support from the National Basic Research Program of China (973 program, Grant No. 2011CB201502), China Postdoctoral
Science Foundation funded project (2014M551978) and Qingdao Postdoctoral Science Foundation funded project are greatly acknowledged.

\section{References}

Ahmaruzzaman, M., Sharma, D.K., 2013. TG-DTA studies on the cracking of petroleum vacuum residue and its co-cracking with plastics, coal, and biomass. Energy Sources Part A 35, 1670-1679.

Anthony, D.B., Howard, J.B., 1976. Coal devolatilization and hydrogastification. AIChE J. 22, 625-656.

Astarita, G., 1989. Lumping nonlinear kinetics: apparent overall order of reaction. AIChE J. 35, 529-532.

Braun, R.L., Burnham, A.K., 1987. Analysis of chemical reaction kinetics using a distribution of activation energies and simpler models. Energy Fuels 1, 153161.

Burnham, A.K., Braun, R.L., 1998. Global kinetic analysis of complex materials. Energy Fuels 13, 1-22.

Cai, J., Han, D., Chen, C., Chen, S., 2010. Application of the golden section search algorithm in the nonlinear isoconversional calculations to the determination of the activation energy from nonisothermal kinetic conversion data. Solid State Sci. $12,829-833$. 
Cai, J.M., Wu, W.X., Liu, R.H., 2013a. Sensitivity analysis of three-parallel-DAEMreaction model for describing rice straw pyrolysis. Bioresour. Technol. 132, 423-426.

Cai, J.M., Wu, W.X., Liu, R.H., Huber, G.W., 2013b. A distributed activation energy model for the pyrolysis of lignocellulosic biomass. Green Chem. 15, 1331-1340.

Chen, D., Gao, X., Dollimore, D., 1993. A generalized form of the Kissinger equation. Thermochim. Acta 215, 109-117.

Chen, H., Liu, N., Fan, W., 2006. Two-step consecutive reaction model and kinetic parameters relevant to the decomposition of Chinese forest fuels. J. Appl. Polym. Sci. 102, 571-576.

Chen, T.J., Wu, J.L., Zhang, J.Z., Wu, J.H., Sun, L., 2014. Gasification kinetic analysis of the three pseudocomponents of biomass-cellulose, semicellulose and lignin. Bioresour. Technol. 153, 223-229.

De Caprariis, B., De Filippis, P., Herce, C., Verdone, N., 2012. Double-Gaussian distributed activation energy model for coal devolatilization. Energy Fuels 26, 6153-6159.

Fiori, L., Valbusa, M., Lorenzi, D., Fambri, L., 2012. Modeling of the devolatilization kinetics during pyrolysis of grape residues. Bioresour. Technol. 103, 389-397.

Gašparovič, L., Labovský, J., Markoš, J., Jelemenský, L., 2012. Calculation of kinetic parameters of the thermal decomposition of wood by distributed activation energy model (DAEM). Chem. Biochem. Eng. Q. 26, 45-53.

Holstein, A., Bassilakis, R., Wójtowicz, M.A., Serio, M.A., 2005. Kinetics of methane and tar evolution during coal pyrolysis. Proc. Combust. Inst. 30, 2177-2185.

Kissinger, H.E., 1957. Reaction kinetics in differential thermal analysis. Anal. Chem. 29, 1702-1706.

Kissinger, H.E., 1956. Variation of peak temperature with heating rate in differential thermal analysis. J. Res. Natl. Bur. Stand. 57, 217-221.

Lai, Z., Ma, X., Tang, Y., Lin, H., 2012. Thermogravimetric analysis of the thermal decomposition of MSW in $\mathrm{N}_{2}, \mathrm{CO}_{2}$ and $\mathrm{CO}_{2} / \mathrm{N}_{2}$ atmospheres. Fuel Process. Technol. 102, 18-23.

Lakshmanan, C.C., White, N., 1994. A new distributed activation energy model using Weibull distribution for the representation of complex kinetics. Energy Fuels 8, 1158-1167.

Li, Q., Zhao, C., Chen, X., Wu, W., Li, Y., 2009. Comparison of pulverized coal combustion in air and in $\mathrm{O}_{2} / \mathrm{CO}_{2}$ mixtures by thermo-gravimetric analysis. $\mathrm{J}$. Anal. Appl. Pyrol. 85, 521-528.

Mani, T., Murugan, P., Mahinpey, N., 2009. Determination of distributed activation energy model kinetic parameters using simulated annealing optimization method for nonisothermal pyrolysis of lignin. Ind. Eng. Chem. Res. 48, 14641467.

Miura, K., Maki, T., 1998. A simple method for estimating $f(E)$ and $k_{0}(E)$ in the distributed activation energy model. Energy Fuels 12, 864-869.

Roque-Diaz, P., University, C., Villas, L., Zh. Shemet, C.V., Lavrenko, V.A., Khristich, V.A., 1985. Studies on thermal decomposition and combustion mechanism of bagasse under non-isothermal conditions. Thermochim. Acta 93, 349-352.

Senneca, O., 2007. Kinetics of pyrolysis, combustion and gasification of three biomass fuels. Fuel Process. Technol. 88, 87-97.

Shen, D., Xiao, R., Gu, S., Luo, K., 2011a. The pyrolytic behavior of cellulose in lignocellulosic biomass: a review. RSC Adv. 1, 1641-1660.

Shen, D.K., Gu, S., Jin, B., Fang, M.X., 2011b. Thermal degradation mechanisms of wood under inert and oxidative environments using DAEM methods. Bioresour. Technol. 102, 2047-2052.

Stamm, A.J., 1956. Thermal degradation of wood and cellulose. Ind. Eng. Chem. Res. $48,413-417$.

Várhegyi, V.B., Bobály, B.Z., Jakab, E., Chen, H., 2010. Thermogravimetric study of biomass pyrolysis kinetics. A distributed activation energy model with prediction tests. Energy Fuels 25, 24-32.

Wang, G., Li, W., Li, B., Chen, H., 2008. TG study on pyrolysis of biomass and its three components under syngas. Fuel 87, 552-558.

White, J.E., Catallo, W.J., Legendre, B.L., 2011. Biomass pyrolysis kinetics: a comparative critical review with relevant agricultural residue case studies. J. Anal. Appl. Pyrol. 91, 1-33.

Yang, H., Yan, R., Chen, H., Lee, D.H., Zheng, C., 2007. Characteristics of hemicellulose, cellulose and lignin pyrolysis. Fuel 86, 1781-1788.

Yang, H., Yan, R., Chen, H., Zheng, C., Lee, D.H., Liang, D.T., 2005. In-depth investigation of biomass pyrolysis based on three major components: hemicellulose, cellulose and lignin. Energy Fuels 20, 388-393.

Zhang, J., Chen, T., Wu, J., Wu, J., 2014. A novel Gaussian-DAEM-reaction model for the pyrolysis of cellulose, hemicellulose and lignin. RSC Adv. 4, 17513-17520.

Zhou, H., Long, Y.Q., Meng, A.H., Li, Q.H., Zhang, Y.G., 2013. The pyrolysis simulation of five biomass species by hemi-cellulose, cellulose and lignin based on thermogravimetric curves. Thermochim. Acta 566, 36-43.

Zou, S., Wu, Y., Yang, M., Li, C., Tong, J., 2010. Pyrolysis characteristics and kinetics of the marine microalgae Dunaliella tertiolecta using thermogravimetric analyzer. Bioresour. Technol. 101, 359-365. 